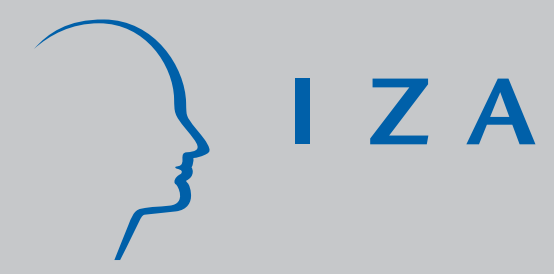

IZA DP No. 3493

Human Capital Externalities and the Urban Wage Premium: Two Literatures and their Interrelations

Benedikt Halfdanarson

Daniel F. Heuermann

J ens Südekum

May 2008 


\title{
Human Capital Externalities and the Urban Wage Premium: Two Literatures and their Interrelations
}

\author{
Benedikt Halfdanarson \\ Statistics Iceland and University of Konstanz \\ Daniel F. Heuermann \\ University of Trier \\ Jens Südekum \\ University of Duisburg-Essen and IZA
}

Discussion Paper No. 3493

May 2008

IZA

P.O. Box 7240

53072 Bonn

Germany

Phone: +49-228-3894-0

Fax: +49-228-3894-180

E-mail: iza@iza.org

Any opinions expressed here are those of the author(s) and not those of IZA. Research published in this series may include views on policy, but the institute itself takes no institutional policy positions.

The Institute for the Study of Labor (IZA) in Bonn is a local and virtual international research center and a place of communication between science, politics and business. IZA is an independent nonprofit organization supported by Deutsche Post World Net. The center is associated with the University of Bonn and offers a stimulating research environment through its international network, workshops and conferences, data service, project support, research visits and doctoral program. IZA engages in (i) original and internationally competitive research in all fields of labor economics, (ii) development of policy concepts, and (iii) dissemination of research results and concepts to the interested public.

IZA Discussion Papers often represent preliminary work and are circulated to encourage discussion. Citation of such a paper should account for its provisional character. A revised version may be available directly from the author. 
IZA Discussion Paper No. 3493

May 2008

\begin{abstract}
Human Capital Externalities and the Urban Wage Premium: Two Literatures and their Interrelations

In this paper we survey the recent developments in two empirical literatures at the crossroads of labor and urban economics: Studies about localized human capital externalities (HCE) and about the urban wage premium (UWP). After surveying the methods and main results of each of these two literatures separately, we highlight several interrelations between them. In particular we ask if HCE can be interpreted as one fundamental cause of the UWP, and we discuss if one literature can conceptually learn from the methods that are used by the other one.
\end{abstract}

JEL Classification: J31, J61, R23, R12

Keywords: local labor markets, agglomeration, human capital externalities, urban wage premium

Corresponding author:

Jens Südekum

University of Duisburg-Essen

Mercator School of Management

Lotharstraße 65

47057 Duisburg

Germany

E-mail: jens.suedekum@uni-due.de 


\section{Introduction}

The rise of cities has marked human history for centuries, in fact for at least as long as written sources can testify. The trend has progressed far and there are no indications this is going to change, with the urban share of world population reaching 49 percent in 2005 and heading for 60 percent in 2030. In more developed regions this share has already reached three quarters (United Nations 2006). Therefore, it is clearly necessary to understand the economics of cities in order to understand the workings of society as a whole.

It has been well known for a long time that earnings of workers are higher in densely populated areas, and written sources indicating this fact date back more than one hundred years (Weber 1899). Attempts at measuring and explaining this urban wage premium (UWP) are on the other hand rather recent with early studies dating back to the 1990s. ${ }^{1}$ The core objective of studies in the UWP literature is to identify the extent to which the density of economic activity in cities has a genuine influence on workers' productivity and to disentangle this "true" effect of urban location on labor productivity from sorting effects and unobserved individual or spatial heterogeneity. At the same time, the literature on localized human capital externalities (HCE), which also deals with the formation of wages, has emerged as a separate branch in the field of labor economics. Rather than focussing on wage effects arising from agglomeration, studies on HCE are concerned with external effects arising from education and typically aim to indentify their magnitude by analysing the influence that the aggregate level of human capital has on individual wages. Like the literature on the UWP, most of the literature on HCE is relatively new, dating mainly from the last 10-15 years, and is still far from having reached a consensus about the existence and the importance of HCE as a determinant of wages. Surprisingly, despite being both concerned with the sources of interregional wage differentials, the two strands of literature have evolved rather separately so far, with little attempts of each strand to build directly on the methods and insights from the other one.

The objective of this paper is therefore to take a closer look at the interrelations between these two lines of research and to describe how they relate to one another. In the next two sections we provide an overview of the literature relating to the UWP and to HCE, respectively, and we discuss the main methodological issues and the main results. Section 4 then looks deeper into the interrelations between the two lines of research and examines their main similarities and differences. We firstly

\footnotetext{
${ }^{1}$ In this paper we use the terms "city" and "metropolitan area" interchangeably.
} 
examine how each literature has dealt with its major methodological problems and investigate to which extent both literatures can learn from each other. Secondly, we discuss their economic interrelations by asking to which extent HCE can be regarded as one fundamental cause behind the UWP. For this discussion we will also set the UWP and HCE into perspective to the broad empirical literature on agglomeration and spatial wage disparities.

After reviewing the current state of art in the literatures on the UWP and on HCE, and by quantifying the magnitudes of the effects typically identified in the literature, we reach the following main conclusions: (1) there exists a "true" UWP of modest but non-negligible size which differs across different types of workers, (2) workers earn higher wages in human capital intensive areas through the workings of HCE, (3) both literatures can be improved by taking into account what the other literature has achieved so far, (4) HCE are one but not the only cause behind the true UWP.

\section{The Urban Wage Premium (UWP)}

Weber (1899) documents rural-urban wage differences in Prussia in the late $19^{\text {th }}$ century, both in terms of numbers of workers earning enough to be taxable and in their income distribution, as well as in terms of the daily earnings of unskilled workers across city sizes. These comparisons all indicate higher earnings in cities. More recent studies confirm that average wages are in fact considerably higher in cities than in rural areas, and that the "raw" UWP is increasing in city size. In a seminal contribution, Glaeser and Maré (2001) report that average wages in metropolitan areas with more than 1 million inhabitants are about 36 percent higher than outside these areas. The raw UWP for smaller cities ranges at about 21 percent. $^{2}$

\subsection{Sorting, unobserved heterogeneity and ability bias}

The fundamental objective in the UWP literature is to disentangle whether higher urban wages are the result of a "true" effect of urban location on the productivity of labor, or whether they arise from

\footnotetext{
${ }^{2}$ The study by Glaeser and Marè (2001) makes use of several data sets: the 1\% Integrated Public Use Microdata Series (IPUMS) from the 1990 Census, a version of the Panel Study of Income Dynamics (PSID), the Current Population Survey (CPS) and the National Longitudinal Survey of Youth (NLSY). Consistent stylized facts for other countries are provided by Möller and Haas (2003) and Lehmer and Möller (2007) for Germany, Di Addario and Patacchini (2008) for Italy, Rice, Venables and Patacchini (2006) for Great Britain, and Combes, Duranton and Gobillon (2008) for France. The latter report that average wages in Paris are 15\% higher than in other large French cities and $60 \%$ higher than in French rural areas.
} 
the fact that workers with more favourable (observable and/or unobservable) characteristics choose to live in cities. There is an abundance of studies showing that regions differ largely in the composition of their workforces, with urban workers being on average more educated than rural ones. As people are typically free to migrate within countries, the location of individuals is not random and systematic differences between rural and urban workforces are clearly the result of endogenous location decisions. The main conceptual difficulty with this sorting mechanism into particular locations is that workers differ not only with respect to observable characteristics, but also along several other dimensions that are not easily observable.

Controlling for basic observable characteristics such as experience or ability as measured by the Armed Forces Qualification Test (AFQT), Yankow (2006) reports a UWP that still ranges between 17 percent and 22 percent for big cities. This is lower than the 36 percent raw UWP, but is still larger than standard estimates for other wage premia, e.g. for union members. These numbers do not necessarily imply, though, that labor is really 17 to 22 percent more productive in cities. The following example illustrates the problem for empirical research: Unobservable motivation or ambition are likely to influence earnings as well, and this ability is only imperfectly captured by AFQT scores. Motivated workers may be attracted to cities if ambition is higher rewarded or if motivated people prefer typical urban amenties such as cultural events, etc. This would lead to endogenous sorting of ambitious workers who are predisposed to higher earnings into urban areas. If these sorting effects are not taken into account observed wage differences between cities and rural areas may be incorrectly interpreted as true productivity effects of urban location.

Instrumenting for urban location has turned out to be difficult due to the lack of suitable instruments that predict urban location but are unrelated to individual wages. Glaeser and Maré (2001) therefore mainly tackle the issue of ability bias by including worker fixed effects in a panel model using individual wage data. They estimate the following specification:

$$
\log \left(W_{i t}\right)=\beta \cdot X_{i t}+\Gamma \cdot L_{i t}+\phi_{i}+\varepsilon_{i t}
$$

$W_{i t}$ is the wage of individual $\mathrm{i}$ in year $\mathrm{t}, X_{i t}$ are basic observable worker characteristics, $L_{i t}$ is a dummy variable indicating if the individual lives in a (large) city, $\phi_{i}$ are worker fixed effect and $\varepsilon_{i t}$ is the error term. Omitting $\phi_{i}$ and, thus, controlling only for observables would bias the coefficient 
for the UWP $(\Gamma)$ if individuals are not randomly distributed across space. Including fixed effects $\phi_{i}$ eliminates the unobserved heterogeneity, but identification of the UWP now relies on individuals who have changed their urban status over time, i.e., on workers who have migrated between cities and rural areas. Using a fixed effects estimator reduces the UWP to around $11 \%$ for large cities, which is around half of the UWP that emerges when only controlling for observables. Yankow (2006) adopts a similar approach to addressing ability bias. He obtains consistent results with the UWP reducing by about 50 percent when including individual fixed effects. ${ }^{3}$

The study by Combes, Duranton and Gobillon (2008) is not specifically focussed on the UWP, but on spatial wage disparities in general. However, their methods and results are of interest here since the issues at hand are similar. Using a two stage estimation procedure on a large panel of French workers, they first regress individual wages on standard worker characteristics and worker fixed-effects, as well as on area-year fixed-effects, industry fixed-effects, and local characteristics of the industry of employment. Combes, Duranton and Gobillon find that about 70 percent of the variation in individual wages can be explained by worker fixed effects alone, suggesting that sorting plays an important role for the explanation of spatial wage disparities. In a second step, they examine the area fixed effects in greater detail by regressing them on time dummies, on variables capturing local endowments, and on local interactions between industries with the latter being interpreted as proxies for different sorts of agglomeration forces. ${ }^{4}$ Combes, Duranton and Gobillon find that these local interaction variables are far more important than local endowments to explain spatial wage disparities. The main message of their study, however, is that most of the variation in spatial wages can be explained by worker fixed effects and, hence, by the sorting of heterogeneous agents across locations. ${ }^{5}$

\footnotetext{
${ }^{3}$ Including fixed effects assumes the existence of a worker-specific "intercept" term for individual wages. This may, however, not be fully adequate, as urban workers may have different experience-wage profiles. Yankow therefore employs an estimator which allows for individual-specific experience profiles as an extension of a simple worker fixed effect. A further extension of this idea is provided in the study by Gould (2007), which is discussed in detail below.

${ }^{4}$ Controlling for industrial composition is motivated by a slightly older literature which investigates the extent to which agglomeration effects arise from either industrial diversity or specialization (see e.g. Glaeser et al 1992 and Wheaton and Lewis 2002), see Combes and Overman (2004) for a survey.

${ }^{5}$ A related earlier study is Duranton and Monastiriotis (2002), who also use a two-step estimation procedure and first clean raw spatial wage differences from differences in individual characteristics. They show that individual returns to educational degrees have become more similar across space and time. Since, however, returns for different levls of education have diverged and since human capital has increasingly agglomerated, interregional inequality has increased on an aggregate level even though individual returns to specific educational attainments have become more similar on a disaggregated level.
} 
Since the contribution by Glaeser and Maré, most studies on the UWP have addressed the problem of ability bias by including AFQT scores (or the like) and individual-specific effect (fixed effect or experience profile) into the regression. Gould (2007) argues, however, that this may not be enough to uncover the causal effects of urban location on individual productivity. The fixed effects model does not assume that current location is uncorrelated with individual characteristics, as the OLS model does, but it implicitly assumes orthogonality of individual characteristics with changes in the workers' location. I.e., economically the fixed effects model assumes that location decisions are uncorrelated with career decisions. However, intuitive reasoning reveals that wage increases after a move to the city do not have to arise because the same worker in the same job is more productive in an urban environment, but they might simply stem from the fact that the worker has changed into a job which offers her better career perspectives, which in turn may cause an instantaneous jump in wages or a faster rate of wage growth over time. ${ }^{6}$ Analogously, the observation that wage premia remain after workers move back to the countryside may reflect improved career perspectives of workers migrating back, rather than true productivity effects. Gould (2007) develops a structural two-stage model which accounts for the self-selection process of workers moving to cities. His findings indicate that for blue collar workers practically no true UWP exists, implying that higher urban wages for blue collar workers arise because more able workers self-select into urban jobs offering them a better career perspective. For white collar workers, in contrast, a genuine UWP of about 11 percent remains. The finding that this wage premium is transferable back to rural areas suggests that cities make white collar workers more productive, which further implies that these workers may regard a job in the city as a human capital investment, which pays off after a move back to the countryside. ${ }^{7}$

\subsection{Costs of living and the UWP in real terms}

A related basic issue about whether the UWP is real concerns the hypothesis that high urban wages may simply compensate for urban disamenities, in particular for the high urban housing prices and costs of living (COL). A principal difficulty when addressing this hypothesis is that comparable

\footnotetext{
${ }^{6}$ An earlier, related argument of sorting processes among unobservable characteristics between industries is provided by Gibbons and Katz (1992), who do, however, find only limited evidence for this type of sorting.

${ }^{7}$ See Glaeser (1992) and Peri (2002) for theoretical models on how cities serve as learning grounds, where young workers accumulate human capital in an early stage of life and then partly move back to rural areas profiting from increased productivity.
} 
regional price data typically does not exist from an official source. Nevertheless, several proxies exist for regional price levels, most notably the price indices developed by the American Chamber of Commerce Research Association (ACCRA). Using this data to deflate nominal wages, Glaeser and Maré (2001) report that in fact no significant UWP in real terms exists for big cities. This observation is important as it helps to understand why workers do not constantly migrate to cities. Still it is puzzling why firms are willing to pay high (nominal) urban wages, even if they sell their products nationwide or even on international markets. In other words, the basic question whether the UWP represents a true effect on labor productivity or ability sorting has to be addressed by using nominal wages rather than real wages. DuMond, Hirsch and MacPherson (1999) point out that a full adjustment of nominal wages with the ACCRA index overstates true COL and, thus, understates real wages in high-priced areas, because consumption patterns change as people substitute goods for local amenities. As a remedy they suggest a partial COL-adjustment based on ACCRA data, which Yankow (2006) uses as corrected price indices in his study on the UWP. Consistent with Glaeser and Maré (2001) he finds that the UWP vanishes in real terms with a full COL-adjustment. However, when using a partial COL-adjustment the UWP reduces to 5 to 12 percent (depending on how unobserved ability is controlled for) and remains significant. Hence, Yankow argues that an UWP exists even after properly controlling for local prices and worker characteristics. This indicates that urban workers ought to be more productive or more able than rural workers, although the COL-adjustment does per se not help to differentiate between productivity and ability bias.

\subsection{Economic mechanisms behind higher urban labor productivity}

Several studies on the UWP go beyond the pure identification of the UWP and aim to shed light on the economic mechanisms responsible for the higher value marginal product of labor in urban environments. This discussion is closely related to the general empirical literature on agglomeration. ${ }^{8}$ The basic problem of this literature is that different theories lead to observationally equivalent outcomes. Most theories predict higher productivity and wages in agglomeration areas.

\footnotetext{
${ }^{8}$ The literature on agglomeration has become extremely voluminous in recent years. Excellent surveys on theory and empirics of different agglomeration forces have been written by Duranton and Puga (2004), Rosenthal and Strange (2004) and Moretti (2004a). The value added of the present survey is that it is specifically focussed on the methodological issues related to those studies that try to identify agglomeration forces by using individual wage data, and on the interrelations between the UWP and the HCE literatures. Furthermore, our survey covers many recent papers and developments in this very active research area that are not covered elsewhere.
} 
They differ, however, in their detailed implications of how (quickly) these urban productivity and wage gains come about.

Since Rosenthal and Strange (2004) provide a comprehensive review of the established theories on the nature and sources of agglomeration economies we only survey them briefly here in order to subsequently relate them to identification strategies based on wage level and wage growth effects. Marshall (1920) identifies knowledge spillovers, sharing of specialized inputs, and constant market for skills as sources of increasing returns from agglomeration. Conceptualizing Marshall's ideas according to their microeconomic foundations, Duranton and Puga (2004) root agglomeration externalities in learning, sharing and matching mechanisms. Learning mechanisms, which are synonymous with the concept of technological HCE discussed below, are facilitated in cities due to the higher number of people and the face-to-face nature of communication. Diversified cities can foster the generation of new ideas and technologies as posited by Jacobs (1969) and Duranton and Puga (2001) in their model of 'nursery cities', where new firms hatch in diversified cities and later move on to more specialized areas. The economies of sharing usually refer to gains from sharing indivisible goods and facilities, from sharing a larger number of specialized inputs, or from sharing risk from labor market fluctuations in a pooled labor market. Matching economies arise if agglomeration improves the quality of matches between workers and jobs. ${ }^{9}$

Empirical studies on the UWP have tried to discriminate between these broad sets of theories by investigating if urban location gives rise to a level or a growth effect on wages, if wage gains are realized mainly with job changes or on-the-job, and, finally, by investigating whether human capital acquired in the city is transferable to rural areas. In these analyses, wage level effects are usually supposed to indicate the presence of matching or sharing externalities which accrue to workers directly after they have moved to the city. If wage gains arise immediately after changing jobs within the city, this allows to draw the conclusion that the UWP arises mainly from matching externalities. If, in contrast, wages grow over time after a move to the city, this is frequently assigned to learning effects, through which workers get more productive over time. If workers keep a higher level of wages even after moving back to rural areas, this is usually taken as further evidence for learning effects being at work in cities.

The first analysis on wage level and growth effects is provided by Glaeser and Maré (2001). Using data on interregional migrants, they include dummy variables for rural-to-urban and urban-to-rural 
respectively, and investigate wages at different time periods before and after the move. While a metropolitan wage premium of around 17 percent exists for non-moving city-dwellers, movers to metropolitan areas seem to quickly realize substantial wage gains of about eight percent already in the first year, which grow to around 12 percent within five years, as compared to rural stayers. The finding of a substantial level effect implies a sudden productivity increase upon moving, which is, however, not sufficient for newcomers to instantaneously reach the productivity level of long-term city workers. Subsequent wage growth of movers indicates gradual wage effects from being in the city, consistent with human capital accumulation leading to a catching up of rural-to-urban migrants with long-run city residents. ${ }^{10}$ An additional finding is that movers out of the city do not appear to suffer a complete loss of the UWP. The evidence thus suggests that the UWP is split between a level effect that is realized immediately upon moving, and a growth effect that is realized only over a period of several years. The level effect amounts to roughly two thirds of the UWP and the growth effect to one third.

The study by Yankow (2006) also starts with a wage level analysis. Controlling for observable worker and labor market characteristics, area COL, and using fixed-effects models to account for unobserved heterogeneity, he concludes that a UWP of around six percent exists for workers in large cities and none for workers for medium-sized cities. In a wage growth analysis, Yankow finds that only part of this UWP is immediately realized by rural-to-urban migrants, while the rest is realized over time when migrants experience significantly faster wage growth than the control group of rural stayers. Yankow also distinguishes between within-job and between-job changes in wages. If improved matching opportunities in cities are a cause of higher urban productivity, between-job wage gains should be higher in urban areas while learning effects should on the other hand lead to higher within-job wage growth. While Yankow's analysis reveals no significant difference in between-job wage growth between urban and rural areas, it turns out that workers in urban areas are more likely to change jobs, which over time can induce faster wage growth.

Wheeler (2006) focuses particularly on wage growth. In contrast to Yankow, he finds job changes in urban areas to be associated with greater changes in log wages than in rural areas, a finding from

\footnotetext{
${ }^{9}$ See Helsley and Strange (1990) for an early formalization of agglomeration economies arising from matching.

${ }^{10}$ Kim (2003) corrorates Glaeser and Maré's empirical findings, but using a spatial equilibrium model he suggests that wage growth effects might also arise from workers learning about their unobservable abilities and, thus, their true productivity, rather than from learning about processes of production; thus, while urban environments do not change a worker's true productivity, they increase knowledge about it and thereby induce successive wage growth.
} 
which he concludes that between-job wage growth is more important than within-job growth in explaining faster growth of urban wages, lending support to matching theories rather than the learning hypothesis. In general, his results indicate that wage growth is positively linked to three different measures of local market scale, i.e. population, population density, and industrial diversity, which is consistent with theories of learning, searching, and matching externalities.

A more complex interpretation of patterns of job changes is provided by Bleakley and Lin (2007), who find regional economic density to have a negative impact on the frequency of intra-regional job changes for all but young workers. They interpret this finding as evidence that cities provide superior matching opportunities, through which young workers change jobs more often up to the perfect match in which they stay thereafter. Workers in rural areas, in contrast, have to change jobs more often for a perfect match to occur since such matches are less probable due to a lower number of potential employers. In a dynamic perspective, these differences in matching opportunities are important as a source of the UWP for two reasons complementing a static increase of productivity arising from better matches. On the one hand, workers' firm or industry specific human capital depreciates faster in the countryside due to a higher rate of job changes. Secondly, young workers in cities have a higher incentive to invest more into firm or sector specific human capital than their rural colleagues since they can expect to stay longer within one firm or industry. ${ }^{11}$

Finally, although the study by Gould (2007) mainly focuses on the proper identification of the causal UWP, it is also informative with respect to the mechanism that drives the true UWP inasmuch as it shows that human capital acquired in the city by white collar workers is fairly well transferable back to rural areas. This finding suggests that cities provide learning opportunities through which white collar workers become sustainably more productive.

\subsection{The UWP for different types of workers}

If the UWP exists, is it identical for all workers in the city or do certain types of workers (highskilled, white-collar) earn a larger premium than others? While most studies focus on the UWP that arises for the average urban worker, some studies explicitly take different types of workers into account. Gould (2007) argues that while white-collar workers receive a sizeable true UWP that is not due to ability bias and is increasing in city experience, higher urban wages for blue-collar

\footnotetext{
${ }^{11}$ The idea that improved matching opportunities in larger markets serve as incentives for an increased investment into education is also a corollary in Wheeler's (2001) theoretical model which he finds to hold empirically.
} 
workers arise exclusively from sorting effects. Consistently, Möller and Haas (2003) find an agglomeration wage premium in Germany for high-skilled but not for low-skilled workers. More generally, one could think that some types of skills (in contrast to degrees of education) receive an extra reward in cities but others do not. Pioneering work comes from Bacolod, Blum and Strange (2008) here, who identify skills along three broad categories, cognitive, people, and motor skills. They construct an index of job skill intensity using the Dictionary of Occupational Titles through which they derive workers' skills from the work they are doing. The authors find evidence that workers with cognitive and people skills, as opposed to those endowed with motor skills, receive an UWP. Their findings also indicate that requirements for cognitive and people skills are higher for white collar professions, while motor skills are frequently associated with blue collar workers.

\subsection{The geographical scope of the UWP}

The distinctive assumption underlying the UWP is that proximity is beneficial. The question that logically arises is "what proximity?" This question regards the spatial reach of agglomeration economies. Most studies use an administrative or official definition of a city or a Standard Metropolitan Statistical Area (SMSA). Glaeser and Maré (2001), for example, define a big city as an SMSA with more than 1 million inhabitants. Similar definitions of a city are used by Yankow (2006) or Gould (2007). Other studies, such as Wheeler (2006) or Combes, Duranton and Gobillon (2008) do not classify regions as urban or rural areas but include measures of market size or density. The latter approach has a long tradition in empirical agglomeration studies with Ciccone and Hall (1996) being a seminal contribution. They argue that doubling the employment density in a local area raises labor productivity by roughly six per cent. A variety of studies adopt a related approach using a gravity-equation to analyze spatial wage structures. These studies (e.g. Hanson 2005, Head and Mayer 2006, Rice, Venables and Patacchini 2006, Amiti and Cameron 2007) typically include market potential as a determinant of productivity or wages in order to investigate if wages are larger near large markets, as posited mainly by the New Economic Geography. ${ }^{12}$ Since market potential is a spatially discounted sum of the market size in other regions, these studies have also something to say about the spatial decay of agglomeration effects. Not all of them use individual wage data, however, which makes them difficult to interpret with respect to their implications for the UWP. 


\subsection{Spatial sorting of industries and firms as sources of the UWP}

A longstanding issue in the debate on the UWP relates to the industrial scale, i.e. to the question whether benefits from agglomeration are rooted in either localization or in urbanization economies. Localization economies, which are usually ascribed to Marshall (1920), Arrow (1962) and Romer (1986), are based on the notion that industrial specialization is beneficial to productivity. Urbanization economies, attributed to Jacobs (1969), assume that metropolitan size and the accompanying diversity of industrial activities lead to higher urban productivity. Studies on whether urban productivity benefits stem from either localization or urbanization economies, which can be traced back to Henderson (1986), have become numerous in recent years and are characterized by a broad variety of methodological approaches. The study by Wheaton and Lewis (2002) is of interest here because it investigates the effects from specialization and concentration on workers' wages by estimating Mincerian wage functions augmented by variables for industrial and occupational concentration and specialization across 220 SMSAs. The authors find strong evidence for wage gains from specialization and concentration, i.e. the more specialized SMSAs are with respect to industries and occupations (specialization), and the higher the share of national employment concentrated in industries and occupations within an SMSA is (concentration), the larger are the wage premia paid to workers in these industries and in these occupations. Raising the level of occupational and industrial specialization (concentration) from the lower bound to the upper bound increases wages by 23 and 30 percent (12 and 16 percent) respectively.

An argument similar to the spatial sorting of industries relates to the spatial sorting of firm types.

Lehmer and Möller (2007) show that firms in urban areas are relatively larger than in the countryside and that larger firms pay higher wages than small firms all else equal. Controlling for firm size, Lehmer and Möller find that the raw UWP of about 15 percent reduces to a genuine UWP of 8 percent and that large firms pay their workers a premium of about 11 percent independent of location. Given the sorting of large firms into cities this intra-firm wage premium is prone to be misinterpreted as being due to urban agglomeration if not properly controlled for.

The idea of spatial sorting is carried further by Mion and Naticcioni (2008), who control for simultaneous worker and firm sorting employing linked employer-employee data (LEED). Their

\footnotetext{
${ }^{12}$ An overview of the New Economic Geography models and their specific mechanisms is provided by Ottaviano and Thisse (2004). The agglomeration effects in these models is typically not rooted in technological externalities, but in market-mediated linkages, i.e. in pecuniary externalities (see Krugman 1991a and 1991b).
} 
results indicate that 75 percent of raw wage variation in Italy can be attributed to the spatial sorting of workers while spatial sorting of firms affects wages only to a minor degree. They furthermore find that while skilled workers and large firms are generally overrepresented in cities and thereby increase urban wages, assortative matching is in general negatively related to market size, i.e. 'good' workers work in 'good' firms mainly in rural areas. Mion and Naticcioni's results emphasize the advantages of using LEED data in order to address the role that assortative matching plays for the UWP. This approach is likely to be pursued much further in this literature.

\section{3.) Human capital externalities (HCE)}

While we are not aware of any other up-to-date survey of the UWP literature, various authors have already taken the effort to review the literature on HCE (see e.g. Davies 2003, Moretti 2004a, Duranton 2006). This allows us to review the HCE literature only briefly. Our main contribution then lies in section 4, where we shed light on the interrelations between the UWP and HCE.

\subsection{Types of $\mathrm{HCE}$}

In general, three different types of externalities have been identified in the literature. Market externalities, which can be further subdivided into technological and pecuniary externalities, are frequently juxtaposed with non-market externalities.

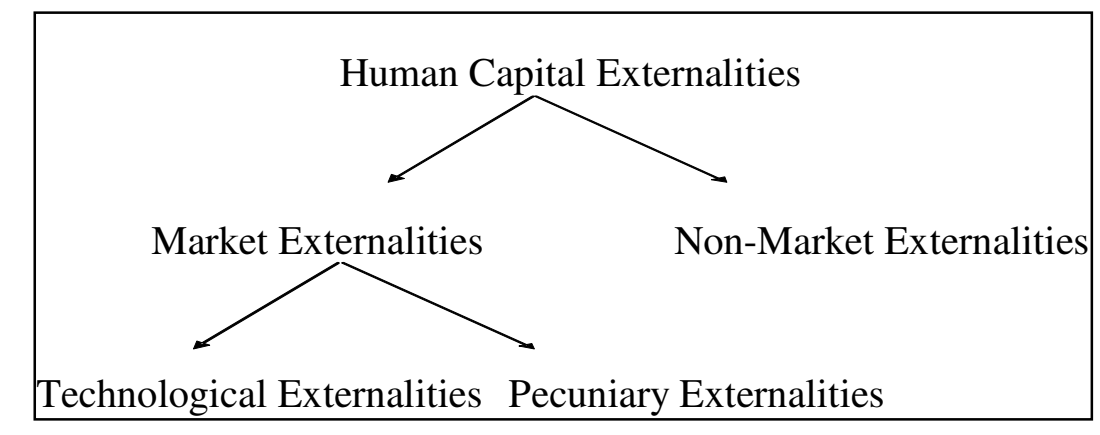

Figure 1: Types of Human Capital Externalities

Established examples for non-market externalities arising from higher levels of human capital are a decrease in crime rates, as well as differences in health-related behaviour and political participation (e.g. Dee 2004). Our primary focus in this survey is on the importance of HCE as a wage 
determining factor, however, hence on market externalities. ${ }^{13}$ Technological human capital externalities arise if educated workers increase the productivity of other workers, for example through processes of informal learning, without being compensated. Jovanovic and Rob (1989) show theoretically that proximity to qualified individuals can increase the acquisition of skills and facilitate the diffusion of knowledge. In contrast to technological HCE, pecuniary HCE arise from market interactions rather than from direct effects on production possibilities. Assuming costly labor market search and complementarity between human and physical capital, Acemoglu (1996) develops a framework in which investment decisions in physical capital are based on expectations on the prospective level of education of the workforce. Since firms anticipate future educational attainments from the contemporary aggregate level of human capital, a more educated workforce leads to an increase in physical capital investment. HCE arise because with asymmetric information a fraction of workers with low human capital will also enjoy a productivity increase through working with an increased stock of physical capital. As factors are paid their marginal product, these workers will realise wage gains because of investment decisions taken by third parties.

Despite the positive connotation of HCE in the literature the occurrence of negative HCE is at least a hypothetical option. Negative effects can arise if the individual level of schooling is mainly interpreted as a signal of productivity by potential employers, even though education has no true effect on productivity (Spence 1973). Thus, individual schooling imposes a cost since third parties are induced to alter their behaviour by an inherently worthless signal.

Through their ubiquitary nature HCE are of prime importance for the design of public policy. However, ample subsidies for the generation of human capital in most Western countries stand in stark contrast to a general ignorance of the size of human capital externalities. Duranton (2006) highlights the potential scale of this uncertainty by pointing out that a misallocation of ten percent of resources invested in education in the US alone would amount to 70 billion USD yearly.

\subsection{Main strategies for identifying $\mathrm{HCE}$}

Decades of research into the returns to education have yielded a large number of studies that identify private returns to education mostly in the magnitude of 8 to 12 percent for every additional year of schooling (Moretti 2004a). Concerning social benefits of education the story is different. In

\footnotetext{
${ }^{13}$ We refer the reader to Moretti (2004a) for a comprehensive overview of the literature on non-market externalities.
} 
the last 15 years numerous attempts to estimate the social return to education have yielded neither clear nor consistent insights, and empirical evidence on their size and even on their existence has remained ambiguous. Some authors have estimated social return to education in the range of one to three percent (e.g. Rauch 1993, Moretti 2004b, 2004c). Others find little evidence for the existence of HCE (Rudd 2000, Acemoglu and Angrist 2000, Ciccone and Peri 2006). An equally controversial issue as the size of social returns to education is the debate over the adequate measures of human capital and empirical methods capable of identifying HCE"

Moretti (2004a) describes three possible strategies for estimating regional HCE, based on interregional differences of either (1) the productivity of firms, (2) costs of land, or (3) workers' wages. The logic of each of these identification frameworks rests on the fundamental spatial equilibrium concept by Roback (1982). If HCE exist, so the argument goes, firms and workers are more productive in cities with high levels of human capital. This in turn should attract firms and workers to these areas. Given a fixed supply of land, this process increases land prices and rents. In equilibrium, both firms and workers must be indifferent between locations. Hence, higher productivity must be offset by higher wages and higher rent.

The biggest problem with the identification approach that uses firm productivity directly is the limited availability of data. Firms' productivity can be compared by either comparing differences in the unit cost functions in two cities with different levels of human capital, holding factor prices constant, or by comparing output of two otherwise identical firms in different cities, holding input quantities constant. Both methods are problematic, however, since data neither on firms' costs of production nor on their input and output is easily available. The problem with land prices is that the assumption of fixed regional quantities need not necessarily hold for land, and less so for the housing stock, which is often used as a proxy for land.

The third and most frequently applied method is a comparison of wages of workers in cities with differing levels of human capital. This identification approach is also most relevant for us since the UWP is also investigated in frameworks relying on individual wage data. In addition, the principal challenge of this approach is very similar to the UWP literature: wages are affected by a multitude of factors, which makes it difficult to identify the true causal effect of HCE on individual wages. An important consideration in the light of the spatial equilibrium concept by Roback (1982) is whether HCE affect only the productivity of labor, or if it also has an effect on the quality of life in a location. If the human capital intensity of a city has a consumption value for individuals, for 
example because a more educated population raises the quality of life due to non-market externalities (lower crime rates, etc.), workers are willing to accept lower wages to live in educated areas. Productivity enhancing effects of human capital would instead capitalize in higher nominal wages. In other words, rents and land prices should be higher in human capital intensive cities provided HCE are positive. The net effect on nominal wages depends, however, on whether human capital is predominantly a productive or consumptive amenity. As a consequence, even an insignificant coefficient of local human capital on individual wages does not necessarily indicate the absence of HCE, since the productive and consumptive effects may simply cancel out.

\subsection{The Mincerian approach}

Most authors have estimated the size of HCE through a comparison of individual wages between cities with varying level of aggregate human capital. A popular approach has been to use Mincerian wage functions augmented by regional variables (Mincer 1974). The earliest attempt to quantify HCE that employs a variation of the Mincer equation is Rauch (1993). Rauch uses an amenity model based on Roback (1982) as a starting point and investigates the impact of aggregate level of human capital, measured by average education and average experience, on individual wages and rents. Rauch augments his wage functions by including the characteristics of the SMSA of residence with average level of human capital being the variable of interest. In addition to wage equations he estimates a hedonic model of land rent, proxied by housing expenditure, employing the following equation

$$
y_{i j}=\alpha+x_{i j} \beta+z_{j} \gamma+\mu_{j}+\varepsilon_{i j}
$$

where $i$ indexes individual workers or dwellings and $j$ indexes SMSA. $y$ is the dependent variable (log wage or $\log$ rent), $x$ is a vector of observed individual characteristics and $z$ is a vector of observed SMSA characteristics. $\mu$ is an error term that captures unobserved SMSA effects and $\varepsilon$ an error term capturing effects of unobserved individual characteristics. Using data from the 1980 census he finds that aggregate education and experience enter the equation positively and significantly at the one percent level, indicating productivity enhancing properties of average human capital levels. Exploring the possibility of omitted variables bias, Rauch controls for area of residence within the US, and for the presence of other local amenities, i.e. cultural activity, weather, and population. Rauch's estimates indicate that an increase of average education by one year 
increases wages significantly by 3.3 percent. In contrast, wages do not seem to be affected by average experience. The effect on rent is estimated at 11.2 percent for a year's increase in average education and 1.3 percent for the same increase in average experience. As his results also indicate private returns of 4.8 percent to an additional year of education, HCE account for as much as almost half the overall returns to education. In sum, Rauch's results support the notion that human capital externalities exist and are of a meaningful size.

Using state level data from 1978-1991 Rudd (2000) repeats Rauch's analysis arguing that state geography is stable over time, which allows for the creation of pooled cross-sections and the use of further controls only available at the state-level. While for single years Rudd finds positive and significant values for the effect of state-wide educational attainment consistent with Rauch's (1993) results for metropolitan areas, he finds no evidence for the existence of externalities after including state fixed effects. This leads him to the conclusion that a state's average education level is merely a good proxy for other unobservable factors affecting productivity.

Dalmazzo and de Blasio (2005) criticize the exclusive focus on wages. The authors argue that it is necessary to consider both wages and rents since consumption externalities from aggregate human capital may counteract wage growth and thereby bias estimates based on wages alone, as argued above. ${ }^{14}$ Dalmazzo and de Blasio's claim of the existence of consumption externalities implies that much of the previous literature may be systematically underestimating the impact of HCE on productivity. Rauch (1993) found the effect of an additional year of local average education on rent to be 11.2 percent. Taking Rauch's estimate of the land share of output to be 6.4 percent, this corresponds to a 0.7 percent increase in total factor productivity that may not be identified in wage equations. Dalmazzo and de Blasio estimate the effect of human capital externalities on land rents and find it to range between six and twenty-four percent.

\subsection{Instrumental variable approaches and the endogeneity of education}

One of the most serious problems in the identification of HCE is a potential endogeneity of education, i.e. causality may not run from education to productivity and wages, neither on the private nor on the social level. Thus, as pointed out by Acemoglu and Angrist (2000) higher incomes might cause more schooling. Just as in the UPW literature another serious concern is that

\footnotetext{
${ }^{14}$ Glaeser, Kolko and Saiz (2001) provide evidence of faster rent growth in cities with more educated populations since 1970, a finding which they assign to existence of consumption externalities.
} 
workers with more favourable (un-)observable characteristics self-select into human capital intensive regions (Moretti 2004b). If workers in human capital intensive regions are better intrinsically motivated and therefore more productive, wage effects from workers' sorting along unobservable characteristics may be confused with HCE. A final aspect of the endogeneity problem are shocks that simultaneously affect a city's earnings and education level. Moretti (2004b) cites the upswing in San Jose in California following the internet boom as an example for these types of shocks, which drive up demand for qualified staff, push up wages, and attract educated workers simultaneously. In this case, aggregate data display an increase in regional human capital and rising overall wages, a combination which is prone to mistakenly be interpreted as the existence of HCE.

Acemoglu and Angrist (2000) address the question of possible reverse causality between wage and education by using past compulsory state schooling laws (CSL) and child-labor laws (CLL) as instrumental variables for average schooling. ${ }^{15}$ Using data from the 1950-1990 censuses on the state level they confirm Rudd's finding that single-year OLS regressions yield larger estimates for social returns to education than fixed effects regressions using longer periods of observation. However, their instrumental variable approach reduces social returns to human capital to statistically insignificant one percent in the 1960-1980 censuses. Adding the 1990 census they identify external returns to education of around four percent, using state-of-birth CLLs as instruments. The authors ascribe this apparent external effect to changes in the census registration in 1990 rather than to increased importance of human capital. One concern that comes to mind considering their study is that their target group consists of white middle-aged males only. One might suspect that this group is on average better educated and may therefore be more of a cause of externalities rather than a beneficiary. Secondly, CSLs might force children to acquire a certain minimum education, but they do not affect choices regarding higher education, which might be the true cause of HCE.

Moretti (2004b) controls for unobserved heterogeneity through individual and city fixed effects using longitudinal data from the 1970 to 1990 censuses and the National Longitudinal Survey of Youth (NLSY) from 1979-1994. To further control for MSA level unobserved heterogeneity and for potential endogeneity of ordinary measures of schooling he employs the presence of a land-grant college and the regional age structure as instruments. The presence of a land-grant college is a

\footnotetext{
${ }^{15}$ Using schooling laws as instruments for aggregate schooling has inspired a series of studies following this approach. A remarkable example is Liu (2007), who uses regional enforcement of Chinese schooling laws as an instrument for regional average schooling and finds localized human capital externalities in China to range between 11 and 13 percent.
} 
relevant instrument for the aggregate level of education since for historical reasons these colleges tend to be located in wealthier areas. Using local age structure as an instrument is based on the observation of a long-term trend of increasing education. The argument is that an SMSA with younger population is likely to be characterized by a higher level of education. Another innovation in Moretti's work is the measure of education employed. He uses the share of college educated workers, rather than the average education level that has been used by the studies previously described. This is important, because the two measures of local human capital are likely to have different effects. Referring to the argument made by Krueger and Lindahl (1999), Moretti suggests that an increase in higher levels of college education leads to productivity growth, while an increase at the lower end (years of schooling) is more likely to have non-market effect such as a reduction in crime rates, etc. This distinction is also relevant in the context of those studies that use CSL as an instrument, since these laws specifically target groups in the lower levels but might have less to do with higher education even if they affect average education. Duranton (2006) offers this as a possible explanation as to why Acemoglu and Angrist (2000) find little evidence of HCE. Pooling all education groups in the NLSY sample Moretti finds a significant and positive effect of about 1.1 to 1.3 percent from a one percentage point increase in the share of college graduates. His results from estimating the external returns to different education groups indicate that changes in the shares of groups with college education cause significant external returns to all groups while increasing the share of those with high-school degree does not. Furthermore, less educated groups generally benefit more from growth in higher education groups than the latter, a finding which is consistent with Moretti's (2004a) notion of imperfect substitution effect discussed below. ${ }^{16}$

An innovative approach to the endogeneity problem is provided by Muravyev (2006), who looks at empirical evidence for HCE in Russia. He argues that average education levels were exogenous with respect to wages at the end of the communist era. The system of wage determination in the USSR had little if anything to do with actual productivity and effectively barred any sorting based

\footnotetext{
${ }^{16}$ Closely related to Moretti (2004a) is Heuermann (2008), who uses the regional number of public schools and of students attending them as instruments for the share of highly qualified workers among regions in Western Germany. Differentiating HCE according to their impact on highly qualified and non-highly qualified workers he identifies social returns to human capital to be in the magnitude of 1.8 percent for highly qualified workers and of .6 percent for nonhighly qualified workers. Heuermann then differentiates the occurrence of HCE between industries and finds that HCE are more pronounced in manufacturing than in the service sector, a finding he relates to the prevalence of pecuniary externalities arising from physical capital intensity in manufacturing. The industry specific analysis also reveals that highly qualified workers seem to benefit from intra-industry knowledge spillovers, while non-highly qualified workers profit mainly from pecuniary externalities arising between industries.
} 
on productivity or wages, which was additionally impeded by migration controls. Muravyev finds that the education level in 1989 is highly correlated with the one in his years of observation, 1994 and 2002, and can thus serve as a valid instrument. In Mincerian regression Muravyev finds a significant increase in individual earnings of around 1.5 percent when the college share in a city increases by one percentage point, a finding which holds after splitting the sample into college graduates and less educated workers, which indicates that benefits from HCE accrue to both groups.

\subsection{Imperfect substitution effects and the constant-composition approach}

Moretti (2004a) has brought the problem of imperfect substitution into the spotlight of empirical research. His argument is based on the notion that increasing the number of high skilled workers changes the relative factor endowments of high-skilled and low-skilled workers in an area. If workers are imperfect substitutes a change in their relative supply affects relative factor prices. These neoclassical supply effects have to be disentangled from any possible external effect of human capital, since otherwise the two impacts on nominal wages are easily confused. In his empirical study, Moretti (2004a) finds a positive effect of local human capital share on earnings of low-skilled and high-skilled individuals. The former finding is consistent with HCE and with imperfect substitution. The latter finding suggests, however, that HCE are present, since the supply of high-skilled labor is positively related to the respective factor price. The evidence even suggests that the HCE are sufficiently strong to compensate possible neoclassical supply effects.

Ciccone and Peri (2006) suggest a 'constant-composition approach' to disentangle HCE from imperfect substitution effects. The proposition is that externalities can be identified as the change in regional average wages when holding regional skill composition constant over time. This method has the advantage that less information is needed, as it does not require instruments for aggregate human capital. Using census data, Ciccone and Peri demonstrate that while the Mincerian approach identifies a positive and significant effect of aggregate human capital on wages, the constant composition method shows no significant effect. This result holds both on the city and state level and across a variety of instruments, including CLS and CLL. Ciccone and Peri's work thus casts some doubt on previously reported results. It must be noted though that since Ciccone and Peri study the same group of workers as Acemoglu and Angrist (2000), i.e. white males aged 40 to 49 , the same caveats apply to their study as did to the latter. 


\subsection{Alternative methods of estimating $\mathrm{HCE}$}

Providing an alternative approach to the studies that have focussed on differences in wages, Moretti (2004c) uses plant-level production functions in order to estimate social returns to human capital. Matching plant records from the Census of Manufacturing and data on workers from the Census of Population he estimates a Cobb-Douglas production function augmented by a measure of aggregate human capital outside the respective industry. Due to data limitations it is not feasible to include human capital within the industry, which would have been a more interesting metric since intuitively it seems probable that (at least technological) externalities are strongest within an industry where similar technologies are used. However, even excluding intra-industry human capital, Moretti finds a one percentage-point increase in college share to be associated with a 0.5-0.7 percent increase in plant-level productivity.

Several studies have approached the effects of human capital from a macro perspective, examining the link between HCE and economic growth. This approach is usually based on Lucas' (1988) model, in which human capital is regarded as the driving force behind growth. Mankiw, Romer and Weil (1992) estimate a Solow-model aggregated by human capital using a multi-country sample. They claim that allowing for human capital in the model makes it much more consistent with international evidence. However, since this strand of research is mostly concerned with differences on the country level, it does not fit our focus on urban and agglomeration economics and thus we only mention it here briefly.

\subsection{Potential reasons for the ambiguity of the evidence on $\mathrm{HCE}$}

Considerable effort has been put into identifying the effects from HCE and various attempts have been made to correct for confounding factors. However, evidence from this research is conflicting both in terms of methods and results. Potential explanations for the conflicting results are numerous since the studies differ in a variety of ways. First of all, the use of panel models can be assumed to make a difference. The discrepancy between Rauch's (1993) and Moretti's (2004b) results can probably partly be assigned to Rauch's use of a single-year sample. The choice of spatial unit is certainly another important factor affecting the results. Since Jaffe, Trajtenberg and Henderson (1993) provide evidence that the geographical spread of knowledge spillovers is limited, differences in the definition of local labor market can be supposed to explain the divergence of the results by 
Moretti (2004b) and Rudd (2000). Analogously, the choice of the measure of human capital, i.e. average years of schooling versus the share of college educated workers, is likely to matter for the results. Finally, as discussed above, differences in the choice of instruments or the sample of workers might well affect the results.

\section{4.) Interrelations Between the HCE and the UWP Literatures}

\subsection{Symmetric development of the literatures}

Although the concepts dealt with in the preceding sections are separate ideas, they share a number of similarities starting with the obvious fact that they both concern the formation of wages and the interregional dynamics of agglomeration. Historically, both strands can be traced back to observations already made in the nineteenth century. Marshall's (1890) famous remark about "the mysteries of the trade being in the air", and Weber's (1899) observations on wage disparities in Prussia can be regarded as fundamental for the development of both lines of inquiry. Yet, in both cases serious attempts of identifying and measuring these phenomena have only come up during the last 10 to 15 years with the availability of adequate micro dataset. Table 1 compares the methodological improvements made in both literatures.

The newer literatures on the UWP and on HCE both started out using augmented versions of the Mincerian wage equation adding regional variables in order to account for urban residence in one case, and the average level of human capital in the other. Subsequently, both approaches have been improved as researchers realized the potential scope of bias and misinterpretation. The next step has therefore been to use fixed effects and instrumental variables in order to control for unobserved heterogeneity and omitted variables. The use of instrumental variables appears to have been much more widespread in the HCE literature, but it is necessary to keep in mind that studies attempting to quantify and explain the UWP have a somewhat shorter history. Another methodological similarity is the use of two stage regressions, first estimating a fixed effect regression and subsequently attempting to decompose the fixed effect itself in a separate regression (Rudd 2000, Combes, Duranton and Gobillon 2008). While the two literatures have evolved in similar ways, the most recent studies in both strands have started to diverge and experimented with novel approaches to deal with each strand's specific problems. Ciccone and Peri's (2006) constant-composition 
approach addresses the imperfect substitution effect that has so far been specific to the HCE literature. Gould's (2007) self-selection model of endogenous location decisions offers a new view on the sorting problem regarding the UWP. Some studies have already started to merge the strands such as Rosenthal and Strange (2006), who estimate the relationship between wages, proximity to human capital, and agglomeration (see section 4.2).

\begin{tabular}{|c|c|c|c|c|c|}
\hline \multicolumn{3}{|c|}{$\underline{\mathbf{U W P}}$} & \multicolumn{3}{|c|}{$\underline{\mathrm{HCE}}$} \\
\hline Study & Approach & Findings & Study & Approach & Findings \\
\hline $\begin{array}{l}\text { Ciccone/Hall } \\
\text { (1996) }\end{array}$ & $\begin{array}{l}\text { Labor productivity } \\
\text { regressions, state level }\end{array}$ & $6 \%$ & Rauch (1993) & $\begin{array}{l}\text { Mincerian wage regressions } \\
\text { on wages and rents }\end{array}$ & $\begin{array}{l}3.3 \% \text { for wages, } \\
11.2 \% \text { for rents }\end{array}$ \\
\hline $\begin{array}{l}\text { Glaeser/Maré } \\
\text { (2001) }\end{array}$ & $\begin{array}{l}\text { Wage regression with } \\
\text { fixed effects }\end{array}$ & $11 \%$ & Rudd (2000) & $\begin{array}{l}\text { State level regression based } \\
\text { on Rauch (1993), fixed } \\
\text { effects decomposition }\end{array}$ & No effects \\
\hline Möller/Haas (2003) & $\begin{array}{l}\text { Quantile wage } \\
\text { regression with focus on } \\
\text { skill levels }\end{array}$ & $\begin{array}{l}2.5 \%, \\
\text { increasing } \\
\text { with skill level }\end{array}$ & $\begin{array}{l}\text { Acemoglu/ } \\
\text { Angrist (2000) }\end{array}$ & $\begin{array}{l}\text { Instrumental variables } \\
\text { (compulsory schooling laws, } \\
\text { child labor laws) }\end{array}$ & $<1 \%$ \\
\hline Yankow (2006) & $\begin{array}{l}\text { COLI adjusted wage } \\
\text { regressions }\end{array}$ & $5-12 \%$ & Moretti (2004b) & $\begin{array}{l}\text { Instrumental variables (age } \\
\text { structure, land grant colleges) }\end{array}$ & $1.1-1.3 \%$ \\
\hline $\begin{array}{l}\text { Lehmer/Möller } \\
\text { (2007) }\end{array}$ & $\begin{array}{l}\text { Wage regressions with } \\
\text { firm size controls }\end{array}$ & $8 \%$ & Moretti (2004c) & $\begin{array}{l}\text { Plant-level production } \\
\text { functions }\end{array}$ & $.5-.7 \%$ \\
\hline Gould (2007) & $\begin{array}{l}\text { Two stage self-selection } \\
\text { model }\end{array}$ & $\begin{array}{l}11 \% \text { for white } \\
\text { collar workers }\end{array}$ & $\begin{array}{l}\text { Dalmazzo/de } \\
\text { Blasio (2005) }\end{array}$ & $\begin{array}{l}\text { Mincerian wage regressions } \\
\text { on rents }\end{array}$ & $6-24 \%$ for rents \\
\hline $\begin{array}{l}\text { Mion/Naticcioni } \\
(2008)\end{array}$ & $\begin{array}{l}\text { Linked Employer } \\
\text { Employee Data }\end{array}$ & $<1 \%$ & $\begin{array}{l}\text { Muravyev } \\
(2006)\end{array}$ & $\begin{array}{l}\text { Instrumental variables (past } \\
\text { education level in Russia) }\end{array}$ & $1.5 \%$ \\
\hline $\begin{array}{l}\text { Combes/Duranton/ } \\
\text { Gobillon (2008) }\end{array}$ & $\begin{array}{l}\text { Decomposition of fixed } \\
\text { effects }\end{array}$ & $3 \%$ & $\begin{array}{l}\text { Ciccone/Peri } \\
(2006)\end{array}$ & $\begin{array}{l}\text { Constant-composition } \\
\text { approach }\end{array}$ & No effect \\
\hline
\end{tabular}

Table 1: History of Thought in the HCE and UWP Literature

\subsection{Problems and solutions shared by both literatures}

Based on the insight of a symmetric development of both literatures we now proceed to systemize and discuss the core problems and the methods used by both literatures to address them. A common challenge for both strands has been the disentangling of the real effects from either urban residence or aggregate human capital from effects caused by unobserved factors. The problem is very similar in both literatures since most of the research has employed hedonic wage equations. The standard model for identifying HCE reads 


$$
\ln W=\alpha+\beta X+\gamma Z+\phi+\varepsilon
$$

where the dependent variable is the log of earnings, $X$ is a vector of individual observable characteristics such as age, education, and gender, and $Z$ includes observable characteristics of the given area, including a measure of aggregate human capital (such as average education, share of educated or otherwise skilled workers). $\phi$ contains unobserved individual characteristics such as motivation, ambition, etc., all of which all might affect wages, but cannot be readily observed. $\varepsilon$ is an error term with the standard assumptions. The size of HCE is displayed by the coefficient of aggregate human capital in the vector $\gamma$.

The standard equation for estimating the effect of urban residence reads

$$
\ln W=\alpha+\beta X+\delta U+\phi+\varepsilon
$$

where all the previous variables are unchanged, except that $U$ either includes dummies for urban residence or a measure of agglomeration density. $\delta$ displays the size of the UWP. The fact that equations (4.1) and (4.2), which are taken from the seminal contributions by Rauch (1993) and Glaeser and Maré (2001), are almost identical underlines the similarity of the initial approaches and indicates the likeness of their problems. If $\phi$ is random and therefore not correlated with any of the other regressors a commonly used and econometrically legitimate option is to ignore it and employ a generalized least squares estimator. In this case, omission would not result in bias. If unobserved individual effects $\phi$ are correlated with some of the other explanatory variables $(X, U$ or $Z)$, this approach is inappropriate since pushing $\phi$ into the error term would introduce partial correlation between $\varepsilon$ and the explanatory variables and thereby lead to inconsistent estimates.

In both the HCE and the UWP literature aggregate human capital or the density of agglomeration is suspected to be correlated with unobserved regional wage determining characteristics, like infrastructure, amenities, or regional policies. In this case an appropriate option is to find suitable instruments for aggregate skill level or the density of agglomeration. A second option is to attempt to proxy for unobserved characteristics by some observable measure. Given the multitude of regional wage determining factors, the use of proxies has frequently turned out to be a highly imperfect option. Both strands of the literature have therefore increasingly relied on regional fixed 
effects and instrumental variables as the main methods of accounting for unobserved characteristics between regions. While regional fixed effects effectively control for factors remaining constant in an area, they are not able to capture regional wage determining variables that change over time and space, like regional union or government policies. The use of instrumental variables, which has turned out to be a more effective strategy here, has in turn frequently raised the question of instrument validity. Some of the instruments used seem far-fetched, like the agestructure for college share, or have been shown to be weak, like compulsory schooling for aggregate education. ${ }^{17}$ In still other cases, no suitable instruments can be found, such as instruments for city residence.

Another serious challenge for both strands of the literature is the integration of market imperfections into empirical investigations. A standard assumption in both strands is that firms and workers are perfectly mobile. This assumption is problematic, however. Numerous studies on interregional migration have shown that workers in the US and even more so in Europe are by far not as mobile as theoretically assumed. However, with segmented or slowly adjusting labor markets regional differences in labor demand and supply become important wage determining factor. To date, it (still) remains for empirical studies in both strands of the literature to explicitly account for these types of rigidities. In a similar vein, there may be other imperfections in labor markets that may cause wages to deviate from marginal product of labor. The typical study on UWP or HCE disregards such institutional differences among regions, one exception being Yankow (2006) who shows that a higher unionization rate in urban areas explains part of interregional wage differences. Three further problems come to mind, which have been dealt with in only one of the two strands. Effects from imperfect substitution described in section 3.4 have been a serious concern in the HCE literature, while they have, in contrast, not featured in research on the UWP. Still, it seems legitimate to ask how changing labor-force compositions would alter the results on the UWP. This is particularly relevant in the light of recent research, which documents large differences in the UWP across skill groups, agglomeration levels, and even quantiles of the wage distribution (Möller and Haas 2003, Gould 2007). If workers of different groups are imperfect substitutes, changes in the relative sizes of the groups are prone to affect wages earned by different groups. Various analyses show that skill levels are on average lower in rural areas, independent of how they are measured

\footnotetext{
${ }^{17}$ Reexamining the results in Angrist and Krueger (1991), Bound, Jaeger and Baker (1995) provide convincing evidence that weak instruments can lead to large inconsistencies in IV estimates.
} 
precisely (Yankow 2006, Möller and Haas 2003). Given this difference, it is obvious that migration will affect the skill composition of at least one area, be it rural or urban. If a random sample of rural workers migrates, this will lower the average skill level in the city. Given imperfect substitution this in turn must change earnings for both groups for two reasons. One is the group specific change in the urban wage premium. The other one is the imperfect substitution effect, which arises in the same way as in the HCE literature. Given this potential duality of effects, future studies on the UWP should take potential bias arising from imperfect substitution effects more seriously than past studies have done.

The second problem arises from the observation that job changes not only seem to play a role in wage growth but are also more frequent in densely populated areas. Distinguishing between level and growth effects has been mainly an issue within the UWP literature where it has been demonstrated that a significant part of the premium is a growth effect, i.e. it arises only after some time spent in the city or on the job. The UWP literature commonly assigns this growth effect to processes of learning and therefore to HCE. The literature on HCE has however been surprisingly reluctant so far to fully integrate an analysis of job changes as a strategy for identifying the nature and the dynamics of processes of social learning. Such integration would, however, not only be advisable in order to better understand how exactly processes of social learning happen to take place, but it is also inherently necessary in order to avoid the danger of biased estimates since it is easy to imagine that a connection exists between the level of human capital and the liveliness of the local labor market, i.e. the ease of job changes. If not controlled for the number of job changes or length of city residence, estimates of the size of $\mathrm{HCE}$ are prone to be underestimated in wage equations because workers in cities may have not yet fully exploited the premium arising from HCE, which will only unfold after a certain amount of time in the city or on the job.

Finally, despite being a crucial issue in both literatures, attempts to control for the sorting of workers along unobservable characteristics have been more widely discussed in the UWP literature. Various studies on the UWP have employed results from the AFQT as proxies for individual ability (Glaeser and Maré 2001, Yankow 2006, Wheeler 2006, Bacolod, Blum and Strange 2008). However, as with unobserved heterogeneity on the regional level, the use of proxies solves the problem of worker sorting only to a minor degree due to the multitude of wage determining factors. 
While the sorting problem can be addressed by the use of individual fixed effects, two important dimensions of worker sorting require more sophisticated methods: the gradual sorting of 'better' workers into 'better' firms, and the sorting of workers into jobs offering them better career perspectives. The former issue has been tackled by Mion and Naticchioni (2008), who by using LEED data show that controlling for the sorting of workers along the lines of firm quality dramatically reduces the UWP. It can reasonably be expected that this issue is relevant for the HCE literature as well. Likewise, simulating the decision making process of rural-urban movers in a twostage model, Gould (2007) shows that for blue-collar workers the alleged UWP can be explained by processes of worker sorting into different career perspectives alone. A similar model could potentially be used in the HCE literature as similar arguments apply for migrants between cities with different human capital intensity.

\subsection{HCE as a cause for the UWP?}

The evidence on HCE reviewed in section 3 suggests that wages increase with the local aggregate level of human capital, which indicates that workers are more productive in human capital intensive environments. Bolstering this finding with indications from numerous studies that cities are endowed with higher levels of human capital than rural areas suggests that HCE have a role to play as a driving force behind the UWP. However, although intuitive, this reasoning does not prove a causal relationship. The core questions to be answered when trying to link both strands of the literature are twofold. On the one hand, we would like to know how much of the urban wage premium can be uniquely attributed to HCE. On the other hand, we wish to learn about the microeconomic mechanisms through which HCE exert their impact on urban wages.

Since the notion of technological HCE mainly revolves around learning effects, there is little reason to expect benefits of HCE to accrue to workers immediately upon moving. Consequently, growth effects of urban residence may indicate the presence of HCE. Wheeler (2006), Yankow (2006), and Lehmer and Möller (2007) draw infererence on learning effects from evidence on wage level and wage growth effects. Lehmer and Möller (2007) show that about one third of the overall UWP of 8.5 percent is a level effect with the remainder being a growth effect. Yankow (2006) finds evidence that about half of the observed wage average wage differential is reaped by movers immediately upon moving while most of the remaining difference is realized in the following five years through growth effects. Increased wage growth for city dwellers can, however, not unambiguously be taken 
as evidence for HCE since it may stem from within-job wage growth and wage growth associated with more frequent job-changes. Of these two, only within-job growth can be regarded as arising from learning effects, while between-job growth is usually interpreted as arising from improving matches of workers to jobs. Yankow (2006) shows that faster urban wage growth is caused by more frequent job changes rather than by faster within-job wage growth. Similarly, Wheeler (2006) argues that while within-job wage growth per se does not appear to be faster in cities, between-job growth is significantly higher in cities than in rural areas. These results indicate that population density facilitates the searching and matching process rather than improving opportunities of social learning and knowledge exchange. While these findings do not necessarily rule out HCE as an explanation for higher urban wages, it must be noted that since the UWP can to a large extent be explained by sorting effects, price level effects, and searching and matching mechanisms, the scope for a substantial role of HCE is shrinking. In general, the limited evidence on technological externalities in the UWP literature is in line with their arguably small size identified in the HCE literature. The big picture arising from scattered evidence thus suggests that while HCE play some role, they are certainly not the whole answer to the question of which forces are responsible for the existence of an UWP.

A further opportunity for identifying the role of HCE for the UWP, which in our view as not been fully exploited yet, is rooted in the debate on potential wage effects from regional specialization and urbanization, which has been pursued mainly within the UWP literature. These studies usually find that a higher degree of specialization and concentration leads to wage gains, which is usually interpreted as evidence for spillovers being limited in industrial scope (Wheaton and Lewis 2002). Though being valuable on their own account, these studies do not have much to say about the interplay between industrial concentration, HCE, and the UWP. Wheeler (2007) is the only study that explicitly focuses on the relation between concentration of industry and human capital externalities. Estimating hedonic wage equations containing both aggregate human capital and level of industry concentration and comparing the coefficients from different combinations of these variables he finds that including both types of explanatory variables in the same regression leaves their respective highly significant effect on wages largely unchanged. Wheeler concludes that localization economies and human capital externalities are fairly distinct phenomena. This finding reveals that neither pecuniary nor technological HCE arise through the concentration of industry alone. In our view a logical extension of his analysis with respect to an identification of the role of 
HCE for the UWP would be a detailed investigation of those workers who change jobs between industries but within cities. Such an analysis of wage growth dynamics after a change of industries within a city can be expected to shed light on the extent to which industries provide fertile grounds for social learning, and on the extent to which workers benefit from intra-industry knowledge spillovers.

A truly spatial view with respect to role of HCE for the UWP is provided by Rosenthal and Strange (2006), who analyze the attenuation of HCE in space. They use geographic information software to create concentric rings which they use as instrumental variables for the employment of both educated and less educated workers at various distances from a given worker's place of work (i.e., within 5 miles, between 5 and 25 miles, and above 25 miles). They then estimate how economic activity in general, and the density of educated workers in particular, affect individual wages. Differencing estimates according to rings of different width allows them to assess the rate at which the influence of agglomeration on wage diminishes with distance. Rosenthal and Strange find that wages in fact increase with economic density (a result consistent with the UWP) and in particular with the density of educated workers (consistent with HCE) with the latter effects displaying a particularly strong spatial gradient. Wages increase strongly if educated workers are located very close by (within 5 miles) and decrease by a factor of 2.5 to three beyond a distance of five miles. ${ }^{18}$ The effect of human capital concentration within 25 miles is considerably weaker. ${ }^{19}$ As for general worker density, Rosenthal and Strange calculate that transforming fifty-thousand lessthan-college educated workers to college educated workers within the five mile zone can be expected to yield a ten percent increase in wages. These results must be taken with a grain of salt, though, since their OLS estimates indicate only a two percent increase for the same change. This substantial difference might be due to weakness of their instruments, indicated by small first-stage F-statistics (smaller than ten with only one exception). Furthermore, these findings are indifferent to whether 500 thousand or 2.5 million people live within an area of 200 square kilometres, which does not seem convincing. On the positive side it deserves mentioning that with their approach

\footnotetext{
${ }^{18} \mathrm{Fu}$ (2007) finds an even more rapid decay with effects from human capital decreasing very quickly beyond three miles, a finding which inspires the author to refer to human capital rich cities as 'smart café cities'.

${ }^{19}$ The argument that spillovers attenuate extremely rapidly has recently been pushed further by Arzaghi and Henderson (2006), who analyze the location decision of advertising agencies in downtown Manhattan. They argue that agencies are consciously willing to locate in extremely expensive neighbourhoods, as they trade off the higher rents with the benefits of being close to other agencies. These type of knowledge spillovers, thus, appear to be extremely strongly localized and capitalize in higher rents rather than in higher wages.
} 
Rosenthal and Strange have laid the cornerstone for an innovative and promising strategy of identifying the relative role of HCE for the UWP.

The only study that sheds light on a particular microeconomic mechanism through which HCE unfold an impact on wages is provided by Charlot and Duranton (2004), who investigate the importance of communication as a knowledge transmission device using a unique dataset on workplace communication among a sample of French workers. Employing standard wage regressions they show that individual communication behaviour significantly affects individual wages over and above regional density and human capital endowments. In a second set of regressions they show that individual communication increases with both city size and overall level of education. However, both aggregate variables display much stronger direct effects on wages, the magnitude of which are in line with general findings in the literature, rather than exerting an impact on wages through individual communication behavior. The direct effect on wages of a one percentage point increase in city population amounts to 1.9 percent, while the indirect effect amounts to only .18 percent. The direct and the communication-mediated wage effect of a one percentage point increase in the regional share of graduates are in the magnitude of .5 percent and .06 percent respectively. These findings render two insights with respect to HCE and the UWP. First, HCE and general economic density coexist as relevant wage determinants and secondly, while communication plays a significant role as a transmission device of knowledge, the direct effect through which agglomeration and aggregate education influence wages is between eight and ten times larger than their indirect effect through communication.

Finally, the discussion in section 3 on whether HCE arise mainly as either production or consumption externalities is important for our take on the importance of HCE as a cause for the UWP. Since with spatially bounded consumption externalities we would expect workers to accept lower wages in human capital rich areas, not controlling for the consumption value of local human capital will lead to an underestimation of the true productivity effect of HCE (Dalmazzo and de Blasio 2005). ${ }^{20}$ Studies aiming to disentangle the relative size of production and consumption externalities have come to consider wages and rents simultaneously. While these studies indicate a substantial impact of regional human capital on productivity (e.g. Rauch 1993), the extent to which

\footnotetext{
${ }^{20}$ One can easily think of crime rates and civic participation as urban amenities which can plausibly be assumed to be influenced by regional human capital. Glaeser and Saiz (2003) suggest that regional skills are a good predictor of productivity growth at the metropolitan level, and of amenity values at the level of municipalities within MSAs.
} 
regional human capital levels carry a consumption value has remained a quite unexplored issue. Since production and consumption externalities from regional human capital affect wages in opposite directions, the lack of research on the role of human capital as an urban consumption amenity turns out to be a root cause for the problem of connecting the UWP to HCE. For this reason, the observation that $\mathrm{HCE}$ are only a minor cause for the existence of the UWP has to be taken as preliminary, as long as it remains unknown to which extent the consumption value of human capital is capitalized in land rents.

\section{Summary and Conclusions}

In this paper we have surveyed two empirical literatures at the cross-roads of urban and labor economics, i.e. studies on the urban wage premium (UWP), and on localized human capital externalities (HCE). Contemplating the current state of art in both strands, we believe that it is fair to draw the following key conclusions:

\section{-Workers earn higher wages in cities.}

Controlling for the variety of confounding factors, and taking various difficulties into account, a "true" urban wage premium between five and ten percent exists for workers in areas of agglomeration. This urban wage premium is partly earned immediately upon moving and partly with time spent in the city. The true UWP tends to be larger for high skilled workers, while sorting explains a smaller portion of their raw UWP compared to low skilled workers.

\section{- Workers earn higher wages in human capital intensive areas.}

While the evidence generated in this strand of literature is somewhat more controversial, several studies indicate small but significant increases in wages resulting from the presence of human capital. These wage gains are frequently in the order of about one to three percent for an additional year of average regional education, or an additional percentage-point in the regional college share.

\section{- Both literature strands can be improved by learning from the methods applied in the respective other strand.}

The two literatures on UWP and HCE have evolved in a rather similar way, progressing from fairly simple hedonic price equations to increasingly sophisticated fixed-effects and instrumental variables 
estimations. In the very recent years, there have been some digressions and experiments with new methods. In the HCE literature the constant composition approach has emerged in order to disentangle effects from externalities from those arising from changing relative supply of imperfectly substitutable factors. In the UWP literature, simulation exercises of workers' optimising behaviour have succeeded in controlling for self-sorting of workers into cities, while the analysis of job-changers has revealed important insights into the sources of the urban wage premium. Given substantial problems still to be addressed in both strands, with imperfect markets, institutional rigidities, assortative matching between firms and workers, and a broad band of endogeneity issues being prime examples, both literatures would certainly benefit from a greater mutual awareness of the attempts and strategies employed by the respective other for solving these problems.

\section{- HCE are one but not the only cause behind the true UWP.}

Numerous attempts have been made in the literature to identify the source of the UWP. Focussing on wage developments after location and job changes and investigating whether human capital acquired in the city is transferable to peripheral regions these analyzes have first and foremost aimed to differentiate knowledge spillovers from matching externalities. These studies provide insightful evidence on the role played by HCE as a driving force behind the UWP. It seems fair to conclude that some parts of the UWP can reasonably be traced back to the existence of HCE. At the same time there is evidence that the UWP is to a large extent rooted in other agglomeration effects which are essentially unrelated to HCE with improved matching possibilities or endogenous market size effects being prime examples. Thus, while being a valid explanatory factor for the existence of a true UWP, HCE can only account for a fraction of it.

The progress which has been made within the last ten to twenty years in both strands of the literature gives reason for hope that the pressing questions in their respective and even more so in their shared fields of investigation will be addressed and answered in the future. 


\section{References}

Acemoglu, Daron. 1996. “A Microfoundation for Social Increasing Returns in Human Capital Accumulation”. Quarterly Journal of Economics 111: 779-804.

Acemoglu, Daron and Joshua Angrist. 2000. "How Large Are Human Capital Externalities? Evidence from Compulsory Schooling Laws", in: Bernanke, B. and K. Rogoff, (eds.) NBER Macroeconomics Annual Cambridge (Mass.): MIT Press.

Amiti, Mary and Lisa Cameron. 2007. "Economic Geography and Wages", Review of Economics and Statistics 89: 15-29.

Angrist, Joshua D. and Alan B. Krueger. 1991. "Does Compulsory School Attendance Affect Schooling and Earnings?", The Quarterly Journal of Economics 106: 979-1014.

Arrow, Kenneth J. 1962. "The Economic Implications of Learning by Doing", Review of Economic Studies 29: 155-173.

Arzaghi, Mohammad and J. Vernon Henderson. 2006. "Networking Off Madison Avenue", Working Paper, Department of Economics, Brown University. http://www.econ.brown.edu/faculty/henderson/papers/MadisonAve101206.pdf.

Bacolod, Marigee, Bernardo S. Blum and William C. Strange. 2008. "Skills in the City", Discussion Paper, http://www.rotman.utoronto.ca/ wstrange/

Bleakley, Hoyt and Jeffrey Lin. 2007. "Thick-Market Effects and Churning in the Labor Market: Evidence from U.S. Cities" Reserve Bank of Philadelphia Working Paper 07-23.

Bound, John, David A. Jaeger and Regina M. Baker. 1995. "Problems with Instrumental Variables Estimation When the Correlation Between the Instruments and the Endogenous Explanatory Variable is Weak", Journal of the American Statistical Association, 90: 443-450.

Charlot, Sylvie and Gilles Duranton. 2004. "Communication Externalities in Cities", Journal of Urban Economics 56: 581-613.

Ciccone, Antonio and Robert E. Hall. 1996. "Productivity and the Density of Economic Activity", American Economic Review 86: 54-70.

Ciccone, Antonio and Giovanni Peri. 2006. "Identifying Human-Capital Externalities: Theory with Applications", Review of Economic Studies 73: 381-412.

Combes, Pierre-Philippe and Henry Overman (2004), "The Spatial Distribution of Economic Activities in the European Union" in: Henderson, J. Vernon and Jacques-Francois Thisse (eds.) Handbook of Regional and Urban Economics vol. 4: Cities and Geography. Amsterdam: Elsevier-North Holland.

Combes, Pierre-Philippe, Gilles Duranton and Laurent Gobillon. 2008. "Spatial Wage Disparities: Sorting Matters!". forthcoming: Journal of Urban Economics (doi:10.1016/j.jue.2007.04.004 )

Di Addario, Sabrina and Eleonora Patacchini. 2008. "Wages and the City. Evidence from Italy", forthcoming: Labour Economics (doi:10.1016/j.labeco.2007.09.003)

Dalmazzo, Alberto and Guido de Blasio. 2005. "Where do human capital externalities end up to?" Banca d'Italia Temi di discussione del Servizio Studi Discussion paper No. 554. http://www.bancaditalia.it/pubblicazioni/econo/temidi/td05/td554_05/td554/tema_554.pdf 
Davies, Jim. 2003. "Empirical Evidence on Human Capital Externalities". Working paper 2003-5. University of Western Ontario, RBC Financial Group Economic Policy Research Institute. http://economics.uwo.ca/centres/epri/wp2003/Davies05.pdf

Dee, Thomas S. 2004. “Are There Civic Returns to Education?”, Journal of Public Economics 9-10: 1697-1720.

DuMond, J. Michael, Barry T. Hirsch and David A. MacPherson. 1999. "Wage Differentials Across Labor Markets and Workers: Does Cost of Living Matter?", Economic Inquiry 37: 577-598.

Duranton, Gilles. 2006. "Human Capital Externalities in Cities: Identification and Policy Issues" in: Arnott, Richard and Daniel McMillen (eds.) A Companion to Urban Economics. Oxford: Blackwell Publishing Ltd.

Duranton, Gilles and Vassilis Monastiriotis. 2002. "Mind the Gaps: The Evolution of Regional Earnings Inequalities in the UK, 1982-1997”, Journal of Regional Science 42: 219-256.

Duranton, Gilles and Diego Puga. 2001. "Nursery Cities: Urban Diversity, Process Innovation, and the Life Cycle of Products", American Economic Review 91: 1454-1477.

Duranton, Gilles and Diego Puga. 2004. "Micro-foundations of Urban Agglomeration Economies" in: Henderson, J. Vernon and Jacques-Francois Thisse (eds.) Handbook of Regional and Urban Economics vol. 4: Cities and Geography. Amsterdam: Elsevier-North Holland.

Fu, Shihe. 2007. "Smart Café Cities: Testing Human Capital Externalities in the Boston Metropolitan Area", Journal of Urban Economics 61: 86-111.

Gibbons, Robert and Lawrence Katz. 1992. "Does Unmeasured Ability Explain Inter-Industry Wage Differentials?", Review of Economic Studies 59: 515-535.

Glaeser, Edward L. et al. 1992. "Growth in Cities", The Journal of Political Economy 100: 11261152.

Glaeser, Edward L. 1999. "Learning in Cities”, Journal of Urban Economics 46: 254-277.

Glaeser, Edward L., Jed Kolko and Albert Saiz. 2001. "Consumer City”, Journal of Economic Geography 1: 27-50.

Glaeser, Edward L. and David C. Maré. 2001. "Cities and Skills", Journal of Labor Economics. 19: 316-342.

Glaeser, Edward L. and Albert Saiz. 2003. "The Rise of the Skilled City", Brooking-Warton Papers on Urban Affairs 5: 47-94.

Gould, Eric D. 2007. "Cities, Workers, and Wages: A Structural Analysis of the Urban Wage Premium" Review of Economic Studies 74: 477-506.

Hanson, Gordon. 2005. "Market potential, increasing returns, and geographic concentration". Journal of International Economics 67: 1-24.

Head, Keith and Thierry Mayer. 2006. "RegionalWage and Employment Responses to Market Potential in the EU", Regional Science and Urban Economics 36: 573-595.

Helsley, Robert and William Strange. 1990. "Matching and Agglomeration Economies in a System of Cities", Regional Science and Urban Economics 20: 189-212. 
Henderson, J. Vernon (1986), "Efficiency of Resource Usage and City Size", Journal of Urban Economics 35: 83-104.

Heuermann, Daniel F. (2008), "Human Capital Externalities in Western Germany", IAAEG Discussion Paper No. 01/2007, Institute for Labor Law and Industrial Relations, University of Trier. http://www.iaaeg.de/documents/Human\%20Capital\%20Externalities.pdf

Jacobs, Jane 1969. The Economy of Cities. New York: Random House.

Jaffe, Adam B., Manuel Trajtenberg and Rebecca Henderson. 1993. "Geographic Localization of Knowledge Spillovers as Evidenced by Patent Citations", Quarterly Journal of Economics 108: 577-598.

Jovanovic, Boyan and Rafael Rob, 1989. "The Growth and Diffusion of Knowledge". Review of Economic Studies, 56: 569-582.

Kim, Bonggeun (2004), "The Wage Gap between Metropolitan and Non-Metropolitan Areas", Paper provided by the Econometric Society, 2004 Australasian Meetings. http://www.econ.canterbury.ac.nz/downloads/jhur_1v.pdf.

Krueger, Alan B. and Mikael Lindahl. 1999. "Education for Growth in Sweden and the World", Swedish Economic Policy Review 6: 289-339.

Krugman, Paul. 1991a. "Increasing Returns and Economic Geography", Journal of Political Economy 99: 493-499.

Krugman, Paul. 1991b. "Geography and Trade”, Cambridge (Mass.): MIT Press.

Lehmer, Florian and Joachim Möller, 2007. "Interrelations between the Urban Wage Premium and Firm-Size Wage Differentials: A Micro Data Cohort Analysis for Germany”. Unpublished manuscript, University of Regensburg.

Liu, Zhiqiang. 2007. "The External Returns to Education: Evidence from Chinese Cities”, Journal of Urban Economics 61: 542-564.

Lucas, Robert E. Jr. 1988. "On the Mechanics of Economic Development", Journal of Monetary Economics 22: 3-42.

Mankiw, N. Gregory, David Romer and David N. Weil. 1992. "A Contribution to the Empirics of Economic Growth", Quarterly Journal of Economics 107: 407-437.

Marshall, Alfred. 1890. Principles of Economics. London: Macmillan

Mincer, Jacob. 1974. Schooling, Experience, and Earnings. New York: National Bureau of Economic Research.

Mion, Giordano and Paolo Naticchioni. 2008. "The Spatial Sorting and Matching of Skills and Firms", forthcoming: Canadian Journal of Economics

Möller, Joachim and Anette Haas 2003. "The Agglomeration Differential Reconsidered: An Investigation With German Micro Data 1984-1997" in: Broecker, J., D. Dohse, R. Soltwedel (Eds.). Innovation Clusters and Interregional Competition. Berlin: Springer.

Moretti, Enrico. 2004a. "Human Capital Externalities in Cities" in: Henderson, J. Vernon and Jacques-Francois Thisse (eds.) Handbook of Regional and Urban Economics vol.4: Cities and Geography. Amsterdam: Elsevier-North Holland. 
Moretti, Enrico. 2004b. "Estimation the social return to higher education: evidence from longitudinal and repeated cross-sectional data", Journal of Econometrics 121:175-212.

Moretti, Enrico. 2004c. "Workers' Education, Spillovers, and Productivity: Evidence from PlantLevel Production Functions", American Economic Review 94: 656-690.

Muravyev, Alexander. 2006. "Human Capital Externalities: Evidence from the Transition Economy of Russia”. DIW Discussion paper No. 629, Berlin.

Ottaviano, Gianmarco and Jacques-Francois Thisse. 2004. "Agglomeration and Economic Geogrpahy" in: Henderson, J. Vernon and Jacques-Francois Thisse (eds.) Handbook of Regional and Urban Economics vol. 4: Cities and Geography. Amsterdam: Elsevier-North Holland.

Peri, Giovanni. 2002. "Young Workers, Learning and Agglomerations", Journal of Urban Economics 52: 582-607.

Rauch, James E. 1993. "Productivity Gains from Geographic Concentration of Human Capital: Evidence from the Cities" Journal of Urban Economics 34: 380-400.

Rice, Patricia, Anthony J. Venables and Eleonora Patacchini. 2006. "Spatial determinants of productivity: Analysis for the regions of Great Britain", Regional Science and Urban Economics 36: 727-752.

Roback, Jennifer. 1982. "Wages, Rents, and the Quality of Life”, Journal of Political Economy 90: 1257-1278.

Romer, Paul M. 1986. "Increasing Returns and Long Run Growth”, Journal of Political Economy 94: 1002-1037.

Rosenthal, Stuart S. and William C. Strange. 2004. "Evidence on the Nature and Sources of Agglomeration Economies" in: Henderson, J. Vernon and Jacques-Francois Thisse (eds.) Handbook of Regional and Urban Economics vol. 4: Cities and Geography. Amsterdam: Elsevier-North Holland.

Rosenthal, Stuart S. and William C. Strange. 2006. "The Attenuation of Human Capital Spillovers: A Manhattan Skyline Approach" Working Paper, Syracuse University

Rudd, Jeremy B. 2000.'Empirical Evidence on Human Capital Spillovers" FEDS Discussion paper 2000-46. http://www.federalreserve.gov/pubs/feds/2000/200046/200046pap.pdf

Spence, Michael. 1973. "Job Market Signalling”, Quarterly Journal of Economics 87: 355-374.

United Nations 2006. "World Urbanization Prospects: The 2005 Revision." http://www.un.org/esa/population/publications/WUP2005/2005WUPHighlights_Final_Report.pd $\underline{f}$

Weber, Adna F. 1899. The Growth of Cities in the Nineteenth Century. $3^{\text {rd }}$ reprint 1968. Ithaca (N.Y): Cornell University Press

Wheaton, William C. and Mark J. Lewis. 2002. "Urban Wages and Labor Market Agglomeration", Journal of Urban Economics 51: 542-562.

Wheeler, Christopher H. 2001. "Search, Sorting, and Urban Agglomeration", Journal of Labor Economics 19: 879-899.

Wheeler, Christopher H. 2006. "Cities and the growth of wages among young workers: Evidence from the NLSY”, Journal of Urban Economics 60(2):162-184. 
Wheeler, Christopher H. 2007. "Do Localization Economies Derive from Human Capital Externalities?” Annals of Regional Science 41: 31-50.

Yankow, Jeffrey J. 2006. "Why do cities pay more? An empirical examination of some competing theories of the urban wage premium", Journal of Urban Economics 60(2): 139-161. 